\title{
Cranioplasty with a low-cost customized polymethylmethacrylate implant using a desktop 3D printer
}

\author{
Jesús A. Morales-Gómez, MD, Everardo Garcia-Estrada, MD, Jorge E. Leos-Bortoni, MD, \\ Miriam Delgado-Brito, MD, Luis E. Flores-Huerta, MD, Adriana A. De La Cruz-Arriaga, ID, \\ Luis J. Torres-Díaz, MI, and Ángel R. Martínez-Ponce de León, MD
}

Department of Neurosurgery, Hospital Universitario “Dr. José Eleuterio González," Monterrey, Nuevo León, México

\begin{abstract}
OBJECTIVE Cranioplasty implants should be widely available, low in cost, and customized or easy to mold during surgery. Although autologous bone remains the first choice for repair, it cannot always be used due to infection, fragmentation, bone resorption, or other causes, which led to use of synthetic alternatives. The most frequently used allogenic material for cranial reconstructions with long-term results is polymethylmethacrylate (PMMA). Three-dimensional printing technology has allowed the production of increasingly popular customized, prefabricated implants. The authors describe their method and experience with a customized PMMA prosthesis using a precise and reliable low-cost implant that can be customized at any institution with open-source or low-cost software and desktop 3D printers.
\end{abstract}

METHODS A review of 22 consecutive patients undergoing CT-based, low-cost, customized PMMA cranioplasty over a 1-year period at a university teaching hospital was performed. Preoperative data included patient sex and age; CT modeling parameters, including the surface area of the implant (defect); reason for craniectomy; date(s) of injury and/or resections; the complexity of the defect; and associated comorbidities. Postoperative data included morbiditiy and complications, such as implant exposure, infection, hematoma, seroma, implant failure, and seizures; the cost of the implant; and cosmetic outcome.

RESULTS Indications for the primary craniectomy were traumatic brain injury (16, 73\%), tumor resection (3, 14\%), infection (1, 4\%), and vascular (2, 9\%). The median interval between previous surgery and PMMA cranioplasty was 12 months. The operation time ranged from 90 to 150 minutes (mean 126 minutes). The average cranial defect measured $65.16 \mathrm{~cm}^{2}$ (range 29.31-131.06 $\mathrm{cm}^{2}$ ). During the recovery period, there was no sign of infection, implant rejection, or wound dehiscence, and none of the implants had to be removed over a follow-up ranging from 1 to 6 months. The aesthetic appearance of all patients was significantly improved, and the implant fit was excellent.

CONCLUSIONS The use of a customized PMMA was associated with excellent patient, family, and surgeon satisfaction at follow-up at a fraction of the cost associated with commercially available implants. This technique could be an attractive option to all patients undergoing cranioplasty.

https://thejns.org/doi/abs/10.3171/2017.12.JNS172574

KEYWORDS cranioplasty; custom polymethylmethacrylate mold; 3D printing; surgical technique

$\mathrm{T}$ HE evolution of cranioplasty parallels the development of technology, the growth of our collective imagination, and our desire to provide maximum benefit with minimum risk and the smallest footprint. ${ }^{12}$ Throughout history, numerous and diverse techniques and novel materials are continuously being developed or improved to properly treat this complex problem. ${ }^{6}$ Ideally, implants should be widely available, low in cost, and customized or easy to mold during surgery. ${ }^{17}$

Although autologous bone remains the first choice for repair, it cannot always be used due to infection, fragmentation, bone resorption, or other causes,$^{28}$ which had led to the use of synthetic alternatives (metals, ceramics, plastics, resorbable polymers, and biomaterials).$^{17}$ 
The most frequently used allogenic material for cranial reconstructions with long-term results is polymethylmethacrylate (PMMA). ${ }^{12}$ Initially manufactured as an industrial material, it was repurposed for use in human calvarial repair by Zander in 1940 and popularized in the published work of Gurdjian et al. soon thereafter ${ }^{4,12,15}$ due to its biocompatibility, availability, low cost, strength, and ability to be premolded. ${ }^{2}$

The advent of computer-assisted design and 3D printing technology has allowed the production of increasingly popular customized, prefabricated implants. ${ }^{4,12}$ Although precise, the use of this technology has not been widely adopted due to limited access to expensive commercial and industrial 3D printers ${ }^{31}$ or expensive commercial customized implants. The addition of increasingly affordable or open-source 3D technology and software makes it possible for neurosurgeons to create in-office, patient-tailored implants.

Our design process for cranioplasty is low cost and feasible in comparison with other described methods. We use open-source image-editing software and desktop 3D printers, and the process innovation we create is efficient in terms of time and resources in order to make it possible for the consultant neurosurgeon to create in-office, patient-tailored implants.

The aim of this study is to share our method and experience with customized PMMA prostheses using a precise and reliable low-cost implant that can be customized at any institution with open-source or low-cost software and a desktop 3D printer.

\section{Methods \\ Patient Population}

We performed a review of 22 consecutive patients undergoing CT-based, low-cost, customized PMMA cranioplasty over a 1-year period at a university teaching hospital (Facultad de Medicina y Hospital Universitario "Dr. José Eleuterio González," Universidad Autónoma de Nuevo León). Institutional review board approval and patient or caregiver consent for photographs were obtained prior to the study's initiation.

\section{Preoperative and Intraoperative Data}

Preoperative data included patient sex and age; CT modeling parameters, including surface area of implant (defect); reason for craniectomy; date(s) of injury and/or resections; complexity of defect; and associated comorbidities. Intraoperative data included surgical technique, location of surgery, drain use, type of closure, and PMMA implant modifications.

\section{Postoperative Data}

Postoperative data included morbidities and complications, such as implant exposure, infection, hematoma, seroma, implant failure, and seizures; cost of the implant; and cosmetic outcome. In addition to the clinical monitoring in the outpatient clinic, patients or their families were contacted by phone to obtain follow-up information and to complete a telephone questionnaire regarding their satisfaction with the PMMA cranioplasty after 1 to 6 months.
We used a simple ordinal rating scale to rate patient or primary caregiver satisfaction with the cosmetic result of the PMMA patient-specific implant as follows: 1, very dissatisfied; 2 , somewhat dissatisfied; 3 , neutral; 4, somewhat satisfied; and 5 , very satisfied. ${ }^{15}$

\section{Modeling Technique}

Cranioplasty CT scanning was performed using a helical scanner. Contiguous 1-mm reconstructed slices were produced from the data volume. The data were then downloaded from the scanner workstation for editing in open-source image-editing software. We use open-source image-editing software and desktop 3D printers, which are briefly described below.

InVesalius is an open-source software that generates 3D medical imaging reconstructions based on a sequence of 2D DICOM files acquired with CT or MRI equipment; the software is internationalized and multiplatform (GNU Linux, Windows, and Macintosh OS). Blender is another free software that we use for modeling the prosthesis; it is cross-platform and runs well on Linux, Windows, and Macintosh computers. MeshLab and MeshMixer are both open-source software that provide tools for editing, cleaning, texturing, and converting the mesh in order to repair them, if necessary. The 2 desktop 3D printers we use are Formlabs Form 2 (Formlabs Inc., from US\$3499.00) and Ultimaker 2+ (from US\$2499.00).

The defects repaired with this process are, in most cases, windows with irregular borders in various anatomical locations. The first step, once the 3D model of the patient's skull is generated, is to obtain the contour of the defect by sketching a line over the external diameter of the craniectomy, or planned craniectomy when needed, and then apply this same step to the internal border. These steps will help in the creation of a precise final piece that matches perfectly with the defect or planned craniectomy (Fig. 1).

Reference curves are drawn to obtain the precise convex form of the external and internal faces of the piece. When the case allows it and there is a healthy side of the skull, reference curves can be mirrored. Once the reference curves are made, a patch is made to form a closed surface or a solid part.

The implant is verified to match perfectly with the skull's perimeter. The next step is to model the mold for the implant using the same open-source image-editing software. When finished, the mold must be exported to a stereolithography format for printing. Then the mold is sterilized, and the implant is customized during or before surgery, pressing the PMMA into the mold when it is in its plastic phase until its complete polymerization. The design process typically lasts between 4 and 5 hours, and the $3 \mathrm{D}$ mold printing lasts on average 10 hours.

\section{Cranioplasty}

Cranioplasty was performed in the standard fashion, the PMMA implant was secured to the skull with self-tapping titanium screws and miniplates, and a Jackson-Pratt wound drain was placed in the subgaleal plane in all cases. When part of the temporal muscle could not be dissected, the temporal part of the implant was modified with ron- 

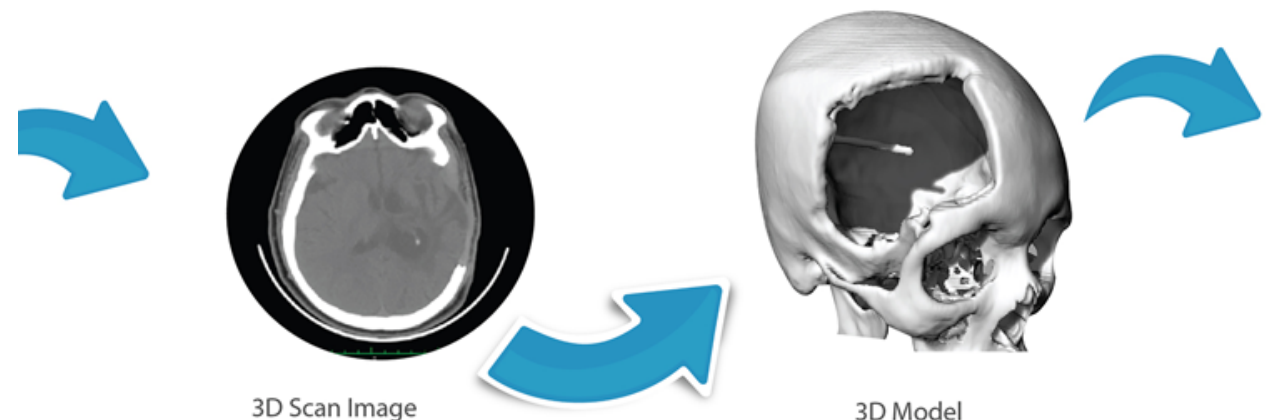

3D Model

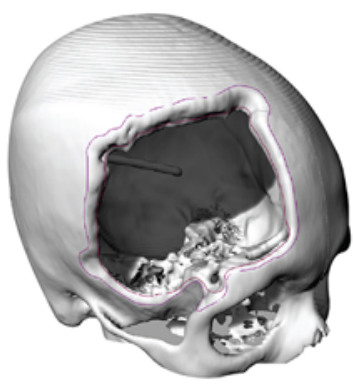

Sketch of perimeter
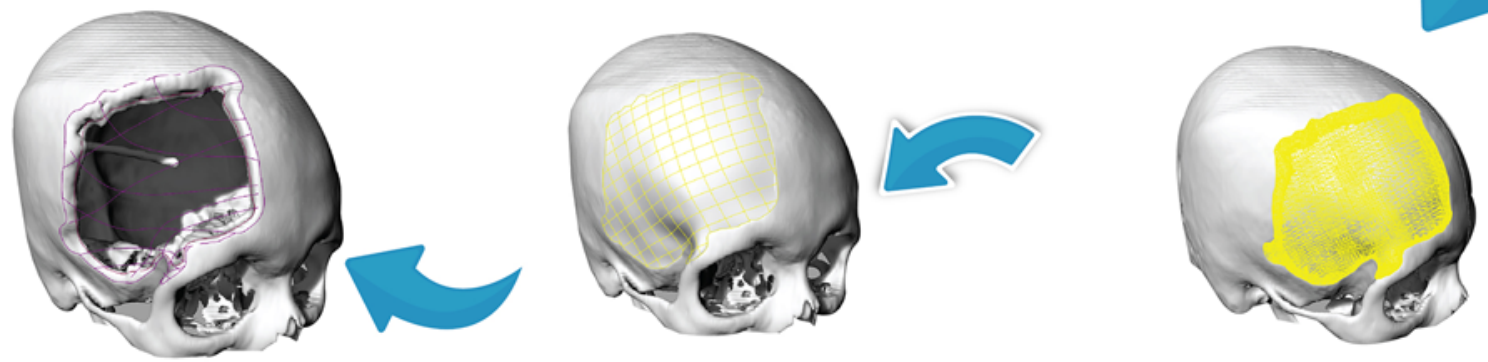

Piece modeling and subtraction

Patch

Sketch of reference curves

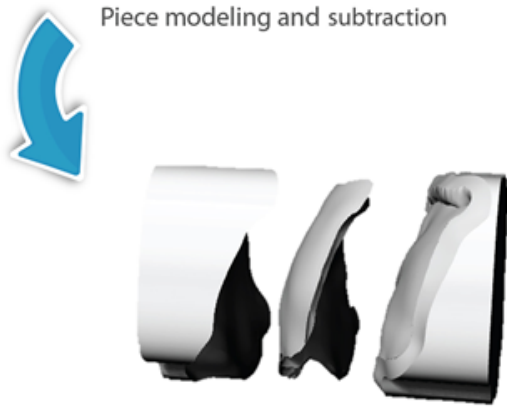

Mold
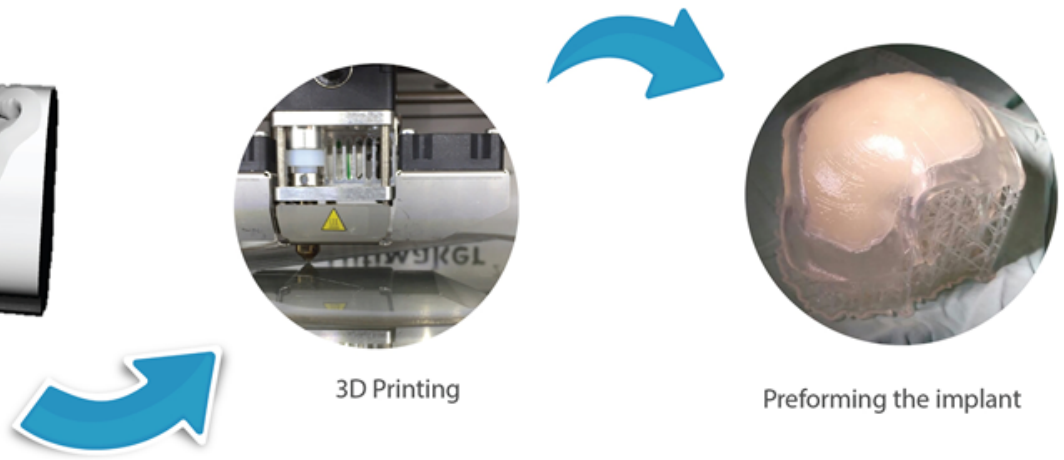

3D Printing

Preforming the implant

FIG. 1. Implant remodeling process. Figure is available in color online only.

geur. All patients received preoperative antibiotics, and a postoperative CT scan was obtained in all patients, usually on the 1st postoperative day.

\section{Results}

A total of 22 consecutive patients were included. Table 1 and Fig. 2 show baseline characteristics. The mean age of the participants was 35.40 years, ranging from 3 to 73 years. Sixteen male and 6 female patients were included. About half of the patients presented with 1 symptom (10, $50 \%$ ). At preoperative examination, $15(68 \%)$ patients had a Glasgow Coma Scale (GCS) score of 15, and 7 (32\%) had a score of 13-14. Indications for the primary craniectomy were traumatic brain injury (TBI) $(16,73 \%)$, tumor resection $(3,14 \%)$, infection $(1,4 \%)$, and stroke $(2,9 \%)$. The median interval between previous surgery and PMMA cranioplasty was 12 months. The operative time ranged from 90 to 150 minutes (mean 126 minutes). The average cranial defect measured $65.16 \mathrm{~cm}^{2}$ (range 29.31-131.06 $\mathrm{cm}^{2}$ ). At postoperative examination, 17 (77\%) patients had a GCS score of 15, and 5 (23\%) had a score of 13-14. The postoperative follow-up period ranged from 1 to 6 months. The costs for the implant ranged from US $\$ 135.23$ to US\$444.44 (mean US\$307.79).

\section{Complications After Cranioplasty}

During the recovery period, there was no sign of infection, implant rejection, or wound dehiscence. None of the implants had to be removed.

\section{Cosmetic Results}

The aesthetic appearance of all patients was significantly improved. Of all 22 participating patients, 14 (63.64\%) were very satisfied with the aesthetic result, and 8 patients (36.36\%) were somewhat satisfied with the aesthetic result. Seven patients were somewhat satisfied because of temporalis muscle atrophy, and 1 patient was somewhat satisfied due to the elevation in the skin caused by the implanted 


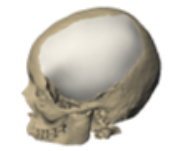

Case 1
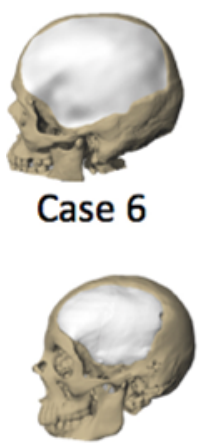

Case 11

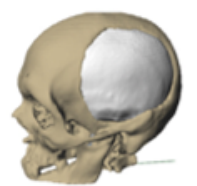

Case 16

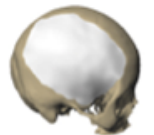

Case 2

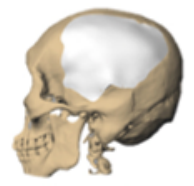

Case 7

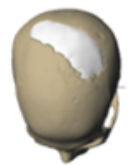

Case 12

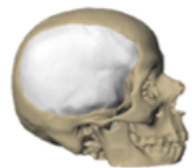

Case 17

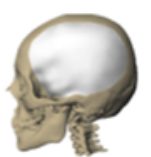

Case 3

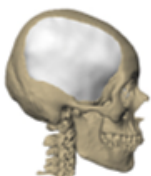

Case 8

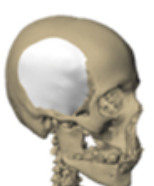

Case 13

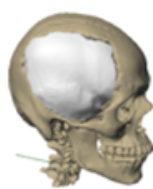

Case 18

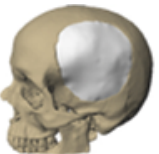

Case 4

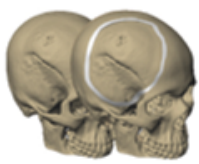

Case 9

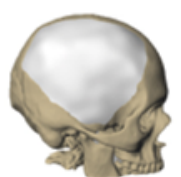

Case 14

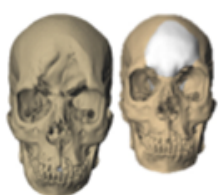

Case 19

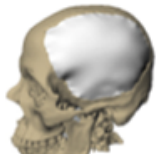

Case 5

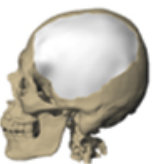

Case 10

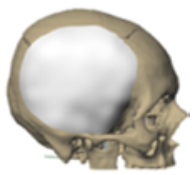

Case 15

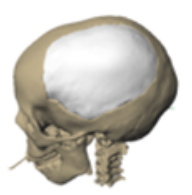

Case 20

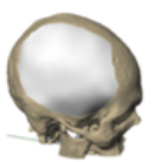

Case 21

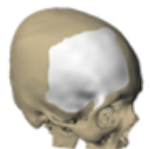

Case 22

FIG. 2. Illustrations showing the customized polymethylmethacrylate implants for each patient. Figure is available in color online only.

miniplate. In general, we evaluated the postoperative appearance 6 months after surgery (Fig. 3). The surgeons reported that the implant fit was excellent and that the results were good in all cases.

\section{Discussion}

Alloplastic cranioplasty techniques using PMMA are a common method of restoring lost cranial bone. ${ }^{11}$ These techniques require modeling of the plastic during its polymerization. This can be difficult with respect to the shape of the skull and thus the aesthetic outcome. One major problem is that, under surgical conditions, free modeling of a large PMMA plastic is difficult. Thus, the process of customizing an implant's design and fabrication has dramatically evolved in just a few decades, from free-hand molding to computer-assisted molding. ${ }^{18}$

Advantages of computer-designed, prefabricated implants have been demonstrated and include improved cosmetic outcome as well as minimization of the procedure time needed for implant insertion. ${ }^{16}$ However, in most series, expensive commercial and industrial 3D printers (approximately US\$37,000-US\$310,000) or expensive com- mercial implants (approximately US\$10,000) 3,5,8,13,18,21,22,26, 30-32 were used, which are prohibitive for use in low- and middle-income countries.

To our knowledge, there is no report of computer-designed customized cranioplasty usage in low- and middleincome countries where the incidence of cranioplasty should be expected to be higher. ${ }^{23,24,27,29}$ In a high-income country, it is expected that the implant would be offered without cost to the patient but not in most middle- and low-income countries.

Different techniques have been reported for customizing a cost-effective implant, with most using the head of the patient prior to or during the surgery and casting. . $^{2,5,7}$, 9,19,20,30,31,33 However, despite their low associated cost, these techniques are not precise or reliable, the original bone flap is needed, and the procedure involves many time-consuming steps. Recently, Abdel Hay et al. published 2 cases in which a template of the external surface was used to mold the implant by hand. ${ }^{1}$ We think that a negative 2-part mold (i.e., inner and outer surfaces) will provide a better result because the polymer takes the precise form planned on the computer. 
TABLE 1. Baseline characteristics

\begin{tabular}{|c|c|c|c|c|c|c|c|}
\hline Case No. & Age (yrs), Sex & Diagnosis & Preop GCS Score & Location & Defect Dimension (cm) & Defect Area $\left(\mathrm{cm}^{2}\right)$ & Price (US\$) \\
\hline 1 & $13, \mathrm{M}$ & $\mathrm{TBI}$ & 15 & Lt FP & $13.00 \times 11.00$ & 71.5 & 362.00 \\
\hline 2 & $17, \mathrm{~F}$ & $\mathrm{TBI}$ & 15 & Rt FTP & $12.39 \times 10.79$ & 66.84 & 362.00 \\
\hline 3 & $12, \mathrm{M}$ & TBI & 15 & Lt FTP & $18.46 \times 14.20$ & 131.06 & 444.44 \\
\hline 4 & $40, M$ & AVM & 15 & Lt FTP & $8.56 \times 8.80$ & 37.66 & 161.11 \\
\hline 5 & $25, \mathrm{M}$ & TBI & 15 & Lt FTP & $12.30 \times 9.10$ & 55.96 & 362.00 \\
\hline 6 & $47, \mathrm{M}$ & TBI & 14 & Lt FTP & $15.00 \times 11.80$ & 88.50 & 444.44 \\
\hline 7 & $50, M$ & TBI & 13 & Lt FTP & $11.32 \times 9.10$ & 51.50 & 300.00 \\
\hline 8 & $45, \mathrm{~F}$ & Ischemic stroke & 15 & Rt FTP & $11.55 \times 9.92$ & 57.28 & 300.00 \\
\hline 9 & $49, \mathrm{~F}$ & Meningioma & 15 & Rt FP & $9.90 \times 11.00$ & 54.45 & 161.11 \\
\hline 10 & $54, \mathrm{M}$ & TBI & 14 & Lt FTP & $13.30 \times 10.40$ & 69.16 & 305.55 \\
\hline 11 & $38, \mathrm{M}$ & TBI & 15 & Lt FTP & $12.11 \times 11.32$ & 68.54 & 255.12 \\
\hline 12 & $16, \mathrm{M}$ & Empyema & 15 & Parietal bilat & $12.21 \times 11.01$ & 67.21 & 297.29 \\
\hline 13 & $63, F$ & Meningioma & 15 & Rt FTP & $10.95 \times 11.26$ & 61.64 & 294.44 \\
\hline 14 & $23, \mathrm{M}$ & $\mathrm{TBI}$ & 15 & Rt FTP & $14.80 \times 12.00$ & 88.8 & 444.44 \\
\hline 15 & $15, \mathrm{M}$ & TBI & 15 & Rt FTP & $13.41 \times 12.60$ & 84.48 & 398.80 \\
\hline 16 & $3, M$ & TBI & 14 & Lt FTP & $11.29 \times 10.12$ & 57.12 & 305.55 \\
\hline 17 & $26, M$ & $\mathrm{TBI}$ & 14 & Rt FTP & $12.47 \times 10.23$ & 63.78 & 311.00 \\
\hline 18 & $28, \mathrm{M}$ & TBI & 15 & Rt FTP & $12.94 \times 10.76$ & 69.61 & 338.88 \\
\hline 19 & $73, \mathrm{M}$ & Mucocele & 14 & Frontal & $8.20 \times 7.15$ & 29.31 & 135.23 \\
\hline 20 & $45, F$ & $\mathrm{TBI}$ & 15 & Lt FTP & $11.30 \times 10.10$ & 57.06 & 298.34 \\
\hline 21 & $34, \mathrm{M}$ & $\mathrm{TBI}$ & 14 & Rt FTP & $10.95 \times 11.26$ & 61.64 & 305.55 \\
\hline 22 & $63, \mathrm{~F}$ & $\mathrm{TBI}$ & 15 & Rt FTP & $9.00 \times 9.00$ & 40.5 & 290.34 \\
\hline
\end{tabular}

$\mathrm{AVM}=$ arteriovenous malformation; $\mathrm{FP}=$ frontoparietal; $\mathrm{FTP}=$ frontotemporoparietal.
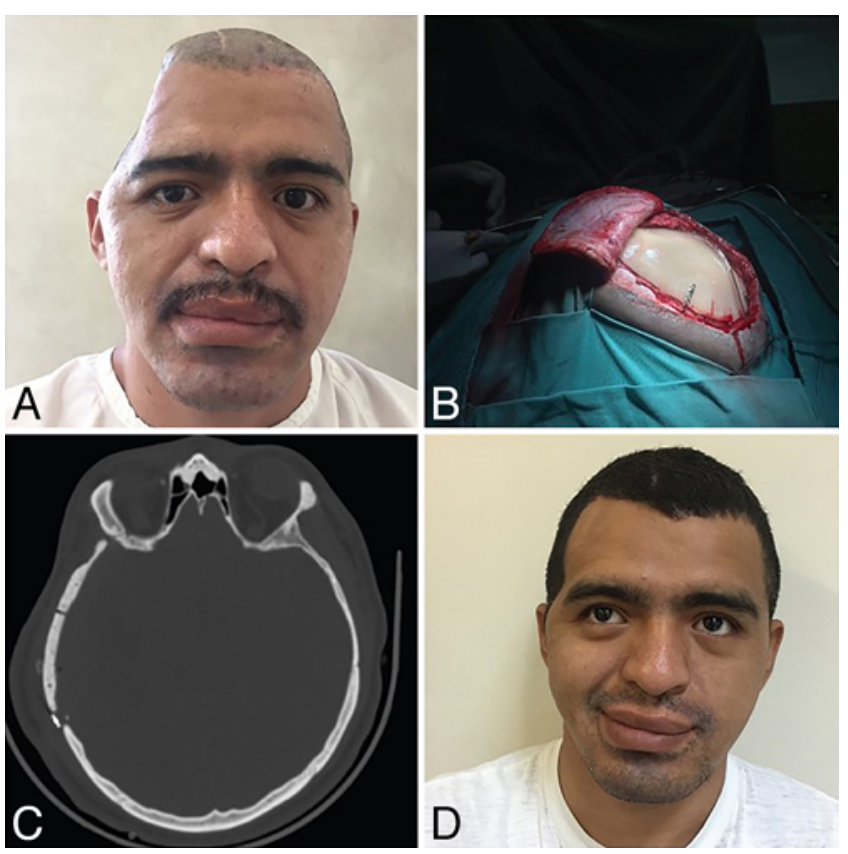

FIG. 3. This 23-year-old patient, who was involved in a motorcycle accident, was diagnosed with an acute subdural hematoma for which a craniectomy was performed. A customized cranioplasty was applied 7 months later with the results shown. Figure is available in color online only.
The 3D printer used in this study costs approximately US\$2500-US\$3500, and the software is open-source, with 48 hours to produce the implant. The process of implant fabrication should be simple, and we condensed steps to create not only a precise implant but also a method that can print surgical guides for planned craniotomy and skull reconstruction after resection of bone tumors in a single surgical session.

To our knowledge, this is the first report that has described a customized PMMA implant designed using open-source planning tools and a desktop 3D printer. ${ }^{31}$ Despite the advent of affordable 3D technology, little attention has been paid to the democratization of technology that open-source and low-cost software and a desktop 3D printer could effect to empower global neurosurgery. ${ }^{10,25} \mathrm{Nev}$ ertheless, by sharing our experience using a reliable and low-cost method that can be performed in any institution with open-source or low-cost software and a desktop 3D printer, we hope to facilitate the advancement of customized cranioplasty. In the end, the democratization of technology will help every novel and creative spirit to develop and embark on future directions in world neurosurgery.

\section{Conclusions}

In our series, the use of customized PMMA was associated with excellent patient, family, and surgeon satisfaction at follow-up at a fraction of the cost associated with commercially available implants. This technique could be an attractive option to all patients undergoing cranioplasty. 


\section{References}

1. Abdel Hay J, Smayra T, Moussa R: Customized polymethylmethacrylate cranioplasty implants using 3-dimensional printed polylactic acid molds: technical note with 2 illustrative cases. World Neurosurg 105:971-979, 979.e1, 2017

2. Akan M, Karaca M, Eker G, Karanfil H, Aköz T: Is polymethylmethacrylate reliable and practical in full-thickness cranial defect reconstructions? J Craniofac Surg 22:12361239,2011

3. Anchieta MV, Salles FA, Cassaro BD, Quaresma MM, Santos BF: Skull reconstruction after resection of bone tumors in a single surgical time by the association of the techniques of rapid prototyping and surgical navigation. Int J CARS 11:1919-1925, 2016

4. Bauermeister AJ, Zuriarrain A, Newman MI: Three-dimensional printing in plastic and reconstructive surgery: a systematic review. Ann Plast Surg 77:569-576, 2016

5. Bhargava D, Bartlett P, Russell J, Liddington M, Tyagi A, Chumas P: Construction of titanium cranioplasty plate using craniectomy bone flap as template. Acta Neurochir (Wien) 152:173-176, 2010

6. Bonfield CM, Kumar AR, Gerszten PC: The history of military cranioplasty. Neurosurg Focus 36(4):E18, 2014

7. Bot GM, Ismail NJ, Usman B, Shilong DJ, Obande JO, Aliu $\mathrm{S}$, et al: Using the head as a mould for cranioplasty with methylmethacrylate. J Neurosci Rural Pract 4:471-474, 2013

8. Brandicourt P, Delanoé F, Roux FE, Jalbert F, Brauge D, Lauwers F: Reconstruction of cranial vault defect with polyetheretherketone implants. World Neurosurg 105:783-789, 2017

9. Caro-Osorio E, De la Garza-Ramos R, Martínez-Sánchez SR, Olazarán-Salinas F: Cranioplasty with polymethylmethacrylate prostheses fabricated by hand using original bone flaps: technical note and surgical outcomes. Surg Neurol Int 4:136, 2013

10. Chae MP, Rozen WM, McMenamin PG, Findlay MW, Spychal RT, Hunter-Smith DJ: Emerging applications of bedside 3D printing in plastic surgery. Front Surg 2:25, 2015

11. Eppley BL: Biomechanical testing of alloplastic PMMA cranioplasty materials. J Craniofac Surg 16:140-143, 2005

12. Feroze AH, Walmsley GG, Choudhri O, Lorenz HP, Grant GA, Edwards MS: Evolution of cranioplasty techniques in neurosurgery: historical review, pediatric considerations, and current trends. J Neurosurg 123:1098-1107, 2015

13. Fiaschi P, Pavanello M, Imperato A, Dallolio V, Accogli A, Capra V, et al: Surgical results of cranioplasty with a polymethylmethacrylate customized cranial implant in pediatric patients: a single-center experience. J Neurosurg Pediatr 17:705-710, 2016

14. Fischer CM, Burkhardt JK, Sarnthein J, Bernays RL, Bozinov O: Aesthetic outcome in patients after polymethylmethacrylate (PMMA) cranioplasty-a questionnaire-based single-centre study. Neurol Res 34:281-285, 2012

15. Gurdjian ES, Webster JE, Brown JC: Impression technique for reconstruction of large skull defects. Surgery 14:876881,1943

16. Hanasono MM, Goel N, DeMonte F: Calvarial reconstruction with polyetheretherketone implants. Ann Plast Surg 62:653-655, 2009

17. Harris DA, Fong AJ, Buchanan EP, Monson L, Khechoyan D, Lam S: History of synthetic materials in alloplastic cranioplasty. Neurosurg Focus 36(4):E20, 2014

18. Huang GJ, Zhong S, Susarla SM, Swanson EW, Huang J, Gordon CR: Craniofacial reconstruction with poly(methyl methacrylate) customized cranial implants. J Craniofac Surg 26:64-70, 2015

19. Jaberi J, Gambrell K, Tiwana P, Madden C, Finn R: Longterm clinical outcome analysis of poly-methyl-methacrylate cranioplasty for large skull defects. J Oral Maxillofac Surg 71:e81-e88, 2013

20. Kung WM, Lin MS: A simplified technique for polymethyl methacrylate cranioplasty: combined cotton stacking and finger fracture method. Brain Inj 26:1737-1742, 2012

21. Lethaus B, Bloebaum M, Koper D, Poort-Ter Laak M, Kessler P: Interval cranioplasty with patient-specific implants and autogenous bone grafts - success and cost analysis. J Craniomaxillofac Surg 42:1948-1951, 2014

22. Manrique OJ, Lalezarzadeh F, Dayan E, Shin J, Buchbinder $\mathrm{D}$, Smith M: Craniofacial reconstruction using patient-specific implants polyether ether ketone with computer-assisted planning. J Craniofac Surg 26:663-666, 2015

23. Marbacher S, Andereggen L, Erhardt S, Fathi AR, Fandino J, Raabe A, et al: Intraoperative template-molded bone flap reconstruction for patient-specific cranioplasty. Neurosurg $\operatorname{Rev}$ 35:527-535, 2012

24. Marbacher S, Coluccia D, Fathi AR, Andereggen L, Beck J, Fandino J: Intraoperative patient-specific reconstruction of partial bone flap defects after convexity meningioma resection. World Neurosurg 79:124-130, 2013

25. Naftulin JS, Kimchi EY, Cash SS: Streamlined, inexpensive 3D printing of the brain and skull. PLoS One 10:e0136198, 2015

26. O'Reilly EB, Barnett S, Madden C, Welch B, Mickey B, Rozen S: Computed-tomography modeled polyether ether ketone (PEEK) implants in revision cranioplasty. J Plast Reconstr Aesthet Surg 68:329-338, 2015

27. Roozenbeek B, Maas AI, Menon DK: Changing patterns in the epidemiology of traumatic brain injury. Nat Rev Neurol 9:231-236, 2013

28. Rosenthal G, Ng I, Moscovici S, Lee KK, Lay T, Martin C, et al: Polyetheretherketone implants for the repair of large cranial defects: a 3-center experience. Neurosurgery 75:523529, 2014

29. Rubiano AM, Carney N, Chesnut R, Puyana JC: Global neurotrauma research challenges and opportunities. Nature 527:S193-S197, 2015

30. Sharavanan GM, Jayabalan S, Rajasukumaran K, Veerasekar G, Sathya G: Cranioplasty using presurgically fabricated presterilised polymethyl methacrylate plate by a simple, cost-effective technique on patients with and without original bone flap: study on 29 patients. J Maxillofac Oral Surg 14:378-385, 2015

31. Tan ET, Ling JM, Dinesh SK: The feasibility of producing patient-specific acrylic cranioplasty implants with a low-cost 3D printer. J Neurosurg 124:1531-1537, 2016

32. Unterhofer C, Wipplinger C, Verius M, Recheis W, Thomé $\mathrm{C}$, Ortler M: Reconstruction of large cranial defects with poly-methyl-methacrylate (PMMA) using a rapid prototyping model and a new technique for intraoperative implant modeling. Neurol Neurochir Pol 51:214-220, 2017

33. Werndle MC, Crocker M, Zoumprouli A, Papadopoulos MC: Modified acrylic cranioplasty for large cranial defects. Clin Neurol Neurosurg 114:962-964, 2012

\section{Disclosures}

The authors report no conflict of interest concerning the materials or methods used in this study or the findings specified in this paper.

\section{Author Contributions}

Conception and design: Morales-Gómez. Acquisition of data: Morales-Gómez, Garcia-Estrada, Leos-Bortoni, Delgado-Brito, Flores-Huerta, De La Cruz-Arriaga. Analysis and interpretation of data: Morales-Gómez, Garcia-Estrada, Leos-Bortoni. Drafting the article: Morales-Gómez, Garcia-Estrada, Leos-Bortoni. Criti- 
cally revising the article: Morales-Gómez, Garcia-Estrada, LeosBortoni. Reviewed submitted version of manuscript: MoralesGómez, Garcia-Estrada, Leos-Bortoni. Approved the final version of the manuscript on behalf of all authors: Morales-Gómez. Statistical analysis: Morales-Gómez, Garcia-Estrada, Leos-Bortoni. Administrative/technical/material support: Morales-Gómez,

Delgado-Brito, Flores-Huerta, De La Cruz-Arriaga, Torres-Díaz,
Martínez-Ponce de León. Study supervision: Morales-Gómez, Martínez-Ponce de León.

\section{Correspondence}

Jesús A. Morales-Gómez: Hospital Universitario “Dr. José Eleuterio González,” Monterrey, Nuevo León, México. jesus.moralesg@ uanl.mx. 